\title{
Supporting Information \\ Understanding the Selectivity of a Moderate Oxidation Catalyst: Hydrogen Abstraction by a Fully Characterized, Activated Catalyst, the Robust Dihydroxo Manganese(IV) Complex of a Bridged Cyclam
}

\author{
Guochuan Yin ${ }^{\dagger}$, Andrew M. Danby ${ }^{\dagger}$, David Kitko ${ }^{\ddagger}$ John D. Carter ${ }^{\ddagger}$, William M. Scheper ${ }^{\ddagger}$ and \\ Daryle H. Busch ${ }^{\dagger *}$ \\ ${ }^{\dagger}$ The University of Kansas, Department of Chemistry, Lawrence, KS 66045. ${ }^{\ddagger}$ The Procter \\ and Gamble Company, Cincinnati, $\mathrm{OH} 45202$. \\ RECEIVED DATE (automatically inserted by publisher); busch@ku.edu
}

\section{Bond dissociation energy (BDE) calculations.}

The $\mathrm{BDE}_{\mathrm{OH}}$ calculations were performed by the method introduced by Bordwell ${ }^{1}$ and adapted by Mayer ${ }^{2}$ (See Scheme $1 \mathrm{~S}$ and $2 \mathrm{~S}$ ).

Hydrogen abstraction reaction--small synthetic scale.

All reagents were obtained from Aldrich and used as received except 1,4-cyclohexadiene which was distilled before use .

In a typical reaction, $0.25 \mathrm{mmol}$ of the manganese(IV) complex was added to $0.5 \mathrm{mmol}$ of 1,4 -cyclohexadiene in 5 $\mathrm{mL}$ of acetone/water (ratio 4:1) solvent in a controlled atmosphere wet box. The reaction mixture was stirred until the purple color of the manganese(IV) species turned to the red brown color of the corresponding manganese(III) species. Quantitative analysis of products was performed by GC using an internal standard, and the identities of the reaction products were confirmed by GC-MS.

\section{Hydrogen abstraction reaction in base-analytical scale.}

In $8 \mathrm{~mL}$ of acetone/water (ratio 4:1), $0.063 \mathrm{~g}(0.1 \mathrm{mmol})$ of manganese(IV) complex was dissolved. The $\mathrm{pH}$ value of the resulting solution was adjusted by $\mathrm{NaOH}$ to $\mathrm{pH} 8.6$ before adding $0.4 \mathrm{~mL}$ ( $2.4 \mathrm{mmol} \mathrm{mmol})$ of diphenylmethane to initiate the reaction. After stirring overnight, the manganese(IV) in the complex was reduced to the corresponding manganese(III) derivative and the $\mathrm{pH}$ value of the solution had changed to 7.6. GC and GC/MS analysis of the reaction mixture showed that no hydrogen abstraction product was formed.

\section{Rate Measurements}

(a) In a typical kinetic experiment, a 20 fold excess of substrate was used. Excess 1,4-cyclohexadiene (CHD, 40 $\mathrm{mM}$ ) and $2 \mathrm{mM}$ of the manganese(IV) complex were dissolved in $10 \mathrm{~mL}$ of acetone/water solvent (ratio 4:1, initial pH 6.1), at r.t. The disappearance of the manganese(IV) species was monitored by UV-visible spectrophotometry and the pseudo first order rate constant $\left(\mathrm{k}_{1}\right)$ was calculated. The same procedure was used in rate determinations for the other substrates listed in Table 1.

(b) To determine the influence of $\mathrm{pH}$ on the rates of the hydrogen abstraction reactions, the oxidations of different substrates by our $\mathrm{Mn}(\mathrm{IV})$ complex were studied in solutions having different selected initial $\mathrm{pH}$ values. $\mathrm{pH}$ values of 4.0 and 8.4 were chosen to reveal the relative reactivities of the two distinct catalyst species capable of performing hydrogen abstractions, $\mathrm{LMn}^{\mathrm{IV}}(\mathrm{OH})_{2}{ }^{2+}$ and $\mathrm{LMn}^{\mathrm{IV}}(\mathrm{O}) \mathrm{OH}^{+}$. These $\mathrm{pH}$ values were chosen on the basis of a well defined $\mathrm{pK}$ value of 6.86 relating these two species and approximate values of $\sim 2$ and $\sim 10$ representing, for $\mathrm{pKa} \approx$ 2, the addition of a third proton to $\mathrm{LMn}^{\mathrm{IV}}(\mathrm{OH})_{2}{ }^{2+}$ (converting one bound $\mathrm{OH}$ to a water molecule) or, for $\mathrm{pKa} \approx 10$ removing the second proton from the same species to form the dioxo complex, $\operatorname{LMn}^{\mathrm{IV}}(\mathrm{O})_{2}$. While the calculations are rendered highly approximate by the dilution of the aqueous medium with acetone because the oxidations were studied in 4:1 acetone:water, the range of acidities should be reasonably represented. For water at a pH of $4, \mathrm{LMn}^{\mathrm{IV}}(\mathrm{OH})_{2}{ }^{2+}$ is expected to be present at $\geq 99 \%$, and the concentrations of both $\mathrm{LMn}^{\mathrm{IV}}\left(\mathrm{OH}_{2}\right) \mathrm{OH}^{3+}$ and $\mathrm{LMn}^{\mathrm{IV}}(\mathrm{O}) \mathrm{OH}^{+}$are estimated to be less than $1 \%$, Similarly, calculations in basic media suggest that the concentration of $\mathrm{LMn}^{\mathrm{IV}}(\mathrm{O})(\mathrm{OH})^{+}$is at the $97-$ $98 \%$ level. Further, about $2-4 \%$ of the manganese is estimated to be present as either the dihydroxo complex, $\mathrm{LMn}^{\mathrm{IV}}(\mathrm{OH})_{2}{ }^{2+}$ or the dioxo complex, $\mathrm{LMn}^{\mathrm{IV}}(\mathrm{O})_{2}$. Accordingly, preliminary rate studies were conducted at $\mathrm{pH} 4.0$ and 8.4 to distinguish between the reactivities of the two forms of the catalyst that are readily available over much of the available $\mathrm{pH}$ range: $\mathrm{LMn}^{\mathrm{IV}}(\mathrm{OH})_{2}{ }^{2+}$ at $\mathrm{pH} 4.0$ and $\mathrm{LMn}^{\mathrm{IV}}(\mathrm{O}) \mathrm{OH}^{+}$at $\mathrm{pH} 8.4$ using $\mathrm{HCl}$ or $\mathrm{NaOH}$ to adjust the initial $\mathrm{pH}$. Buffers were not used in these preliminary studies because of the complications they introduce. Specifically, phosphate and carbonate buffers complex with the metal ions, displacing $\mathrm{OH}$ groups, while some organic buffers can also coordinate to the metal ion and some are subject to oxidation. Since the manganese(IV) complexes decompose slowly in the acidic solution and are quite unstable in basic solution (see Figure 7S-9S), the calculated rate constants have been corrected for the separately determined catalyst decomposition rates in the absence of the substrate.

The initial $\mathrm{pH}$ of the $\mathrm{Mn}(\mathrm{IV})$ solution in acetone/water (ratio 4:1) was adjusted to $\mathrm{pH} 4.0$ or 8.4 before initiation of the reaction by addition of the substrate. The results of these studies are very clear. The hydrogen abstraction reaction proceeds much faster in base (for xanthene, $\mathrm{k}_{1}=(2.45 \pm 0.02) \times 10^{-3} \mathrm{~s}^{-1}$ ) than in acidic solution (for xanthene, $\mathrm{k}_{1}$ $\left.=(1.59 \pm 0.01) \times 10^{-5} \mathrm{~s}^{-1}\right)$, demonstrating the fact that the $\mathrm{Mn}^{\mathrm{IV}}=\mathrm{O}$ moiety performs hydrogen abstraction more rapidly than does $\mathrm{Mn}^{\mathrm{IV}}-\mathrm{OH}$, even though there are two $\mathrm{OH}$ groups in the dihydroxo complex. These rates differ by an average factor of $14 \pm 2$ and this focuses attention on the relative intrinsic efficacies of oxidizing species differing only in the 
level of their protonation in such fundamental chemical processes as hydrogen abstraction. This phenomenon is also illustrated in these systems by the observation that the manganese(IV) complex is relatively stable in neutral to weakly acidic solution where the dominant species is $\mathrm{LMn}^{\mathrm{IV}}(\mathrm{OH})_{2}{ }^{2+}$, but quite unstable in basic solution where both $\mathrm{LMn}^{\mathrm{IV}}(\mathrm{O})(\mathrm{OH})_{2}{ }^{+}$and $\mathrm{LMn}^{\mathrm{IV}}(\mathrm{O})_{2}$ exist. In earlier work it has been shown that at high $\mathrm{pH}$ values about $10 \%$ of the complex decomposes due to ligand destruction and $\sim 90 \%$ is recovered as the manganese(III) complex of the intact ligand. ${ }^{4}$ This decomposition is attributed to the inherent instability of the dioxo complex, $\mathrm{LMn}^{\mathrm{IV}}(\mathrm{O})_{2}$

\section{Reference:}

1. Bordwell, F. G.; Cheng, J. P.; Harrelson, J. A. J. Am. Chem. Soc. 1988,110, 1229.

2. Mayer, J. M. Acc. Chem. Res., 1998, 37, 441; Mayer, J.M. et al., Mayer, J.M., et al., J. Mol. Catal. A Chem. 2006, 251, 24-33.

3. Goldsmith, C. R.; Jonas, R. T.; Stack, T.D. J. Am. Chem. Soc. 2002, 124, 83.

4. Yin, G.; McCormick, J. M.; Buchalova, M.; Danby, A. M.; Rodgers, K.; Smith, K.; Perkins, C.; Kitko, D.; Carter, J.; Scheper, W. M.; Busch, D. H. Inorg. Chem., 2006, 45, 8052. 
Scheme 1S

$$
\begin{aligned}
& \mathrm{Mn}^{\mathrm{IV}} \mathrm{L}(\mathrm{OH})_{2}{ }^{2+}+\mathrm{e}^{-} \\
& \longleftrightarrow \mathrm{Mn}^{\mathrm{III}} \mathrm{L}(\mathrm{OH})_{2}^{+} \\
& \mathrm{E}^{\mathrm{O}}=+0.756 \mathrm{~V} \Delta \mathrm{G}_{1}{ }^{0}=-17.4 \\
& \mathrm{kcal} / \mathrm{mol} \\
& 1 / 2 \mathrm{H}_{2(\mathrm{~g})} \longrightarrow \mathrm{H}^{+}+\mathrm{e}^{-} \\
& \mathrm{Mn}^{\mathrm{III} L(\mathrm{OH})_{2}{ }^{+}+\mathrm{H}^{+} \longleftrightarrow \mathrm{Mn}^{\mathrm{III}} \mathrm{L}\left(\mathrm{H}_{2} \mathrm{O}\right)(\mathrm{OH})^{2+} \mathrm{pKa}=5.87 \begin{array}{l}
\Delta \mathrm{G}_{2}{ }^{\mathrm{O}}=-8.0 \\
\mathrm{kcal} / \mathrm{mol}
\end{array}} \\
& \mathrm{H}^{\cdot} \longrightarrow 1 / 2 \mathrm{H}_{2(\mathrm{~g})} \\
& \mathrm{Mn}^{\mathrm{IV}} \mathrm{L}(\mathrm{OH})_{2}{ }^{2+}+\mathrm{H}^{\cdot} \longleftrightarrow \mathrm{Mn}^{\mathrm{III}} \mathrm{L}(\mathrm{HO})(\mathrm{HO}-\mathrm{H})^{2+} \\
& \Delta H^{\circ}=\Delta G^{0}+T \Delta S^{0}=-82.4+(298) \times\left(-1.9 \times 10^{-3}\right)=-83.0 \mathrm{kcal} / \mathrm{mol} \\
& \mathrm{BDE}_{\mathrm{OH}}=83.0 \mathrm{kcal} / \mathrm{mol}
\end{aligned}
$$


Scheme 2S

$$
\begin{aligned}
& \mathrm{Mn}^{\mathrm{IV}} \mathrm{L}(\mathrm{OH})_{2}{ }^{2+}+\mathrm{e}^{-} \longleftrightarrow \mathrm{Mn}^{\mathrm{III}} \mathrm{L}(\mathrm{OH})_{2}{ }^{+} \quad \mathrm{E}^{\mathrm{O}}=+0.756 \mathrm{~V} \underset{\mathrm{kcal} / \mathrm{mol}}{\Delta \mathrm{G}_{1}{ }^{0}=-17.4} \\
& 1 / 2 \mathrm{H}_{2(\mathrm{~g})} \longrightarrow \mathrm{H}^{+}+\mathrm{e}^{-} \\
& \left.\mathrm{Mn}^{\mathrm{IV}} \mathrm{L}(\mathrm{O})(\mathrm{OH})^{+}+\mathrm{H}^{+} \longleftrightarrow \mathrm{Mn}^{\mathrm{IV} L(O H}\right)_{2}{ }^{2+} \quad \mathrm{pKa}=6.86 \quad \begin{array}{l}
\Delta \mathrm{G}_{2}{ }^{\mathrm{O}}=-9.3 \\
\mathrm{kcal} / \mathrm{mol}
\end{array} \\
& \mathrm{H}^{\cdot} \longrightarrow 1 / 2 \mathrm{H}_{2(\mathrm{~g})} \quad \Delta \mathrm{G}_{3}{ }^{\mathrm{O}}=-57 \\
& \mathrm{kcal} / \mathrm{mol}
\end{aligned}
$$

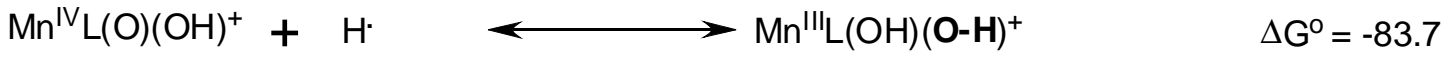

$$
\begin{aligned}
& \mathrm{kcal} / \mathrm{mol} \\
& \begin{array}{c}
\Delta \mathrm{H}^{\circ}=\Delta \mathrm{G}^{\circ}+\mathrm{T} \Delta \mathrm{S}^{\circ}=-83.7+(298) \times\left(-1.9 \times 10^{-3}\right)=-84.3 \mathrm{kcal} / \mathrm{mol} \\
\mathrm{BDE}_{\mathrm{OH}}=84.3 \mathrm{kcal} / \mathrm{mol}
\end{array}
\end{aligned}
$$




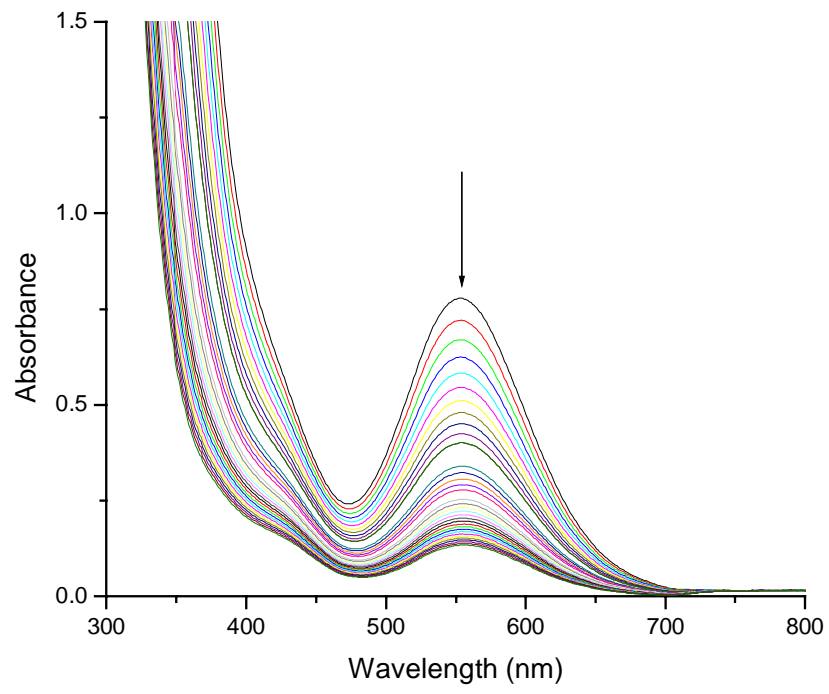

Figure 1S Kinetic process for hydrogen abstraction from 1,4-cyclohexadiene with manganese(IV) complex. Conditions: solvent: acetone/water (1:1), $1 \mathrm{mM}$ manganese(IV) complex, $20 \mathrm{mM}$ 1,4-cyclohexadiene, r.t. $15 \mathrm{~min} / \mathrm{scan}$. 


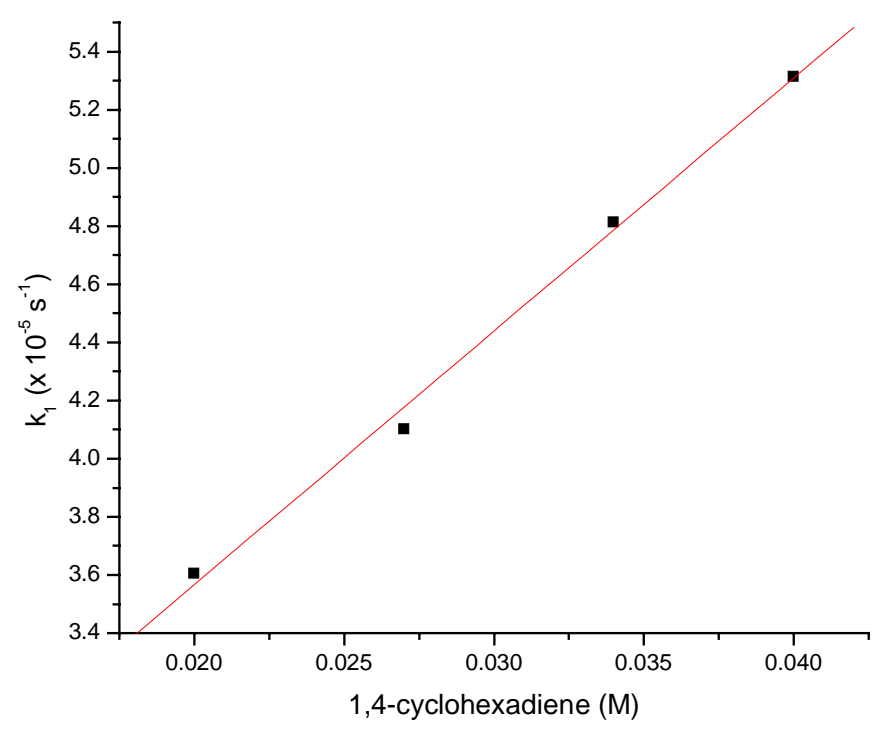

Figure $2 \mathrm{~S}$ First-order rate constants for the reduction of $\mathrm{Mn}\left(\mathrm{Me}_{2} \mathrm{EBC}\right)^{4+}$ (initial concentration: $2 \mathrm{mM}$ ) in the presence of 1,4-cyclohexadiene (CHD) in simple acetone/water (ratio 4:1) solution at $24^{\circ} \mathrm{C} . \mathrm{k}_{2}=8.72 \times 10^{-4} \mathrm{M}^{-1} \mathrm{~s}^{-1}$. 


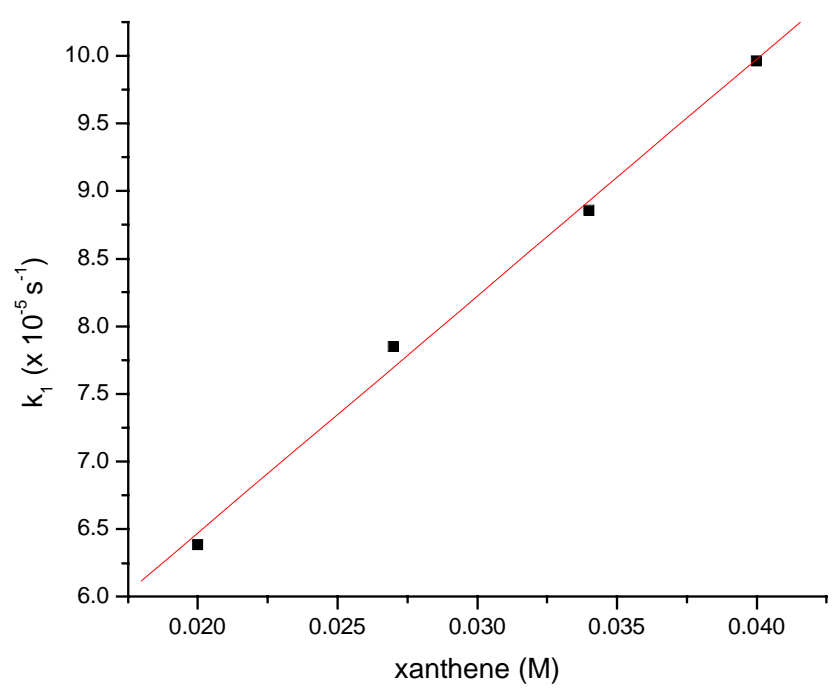

Figure 3S First-order rate constants for the reduction of $\mathrm{Mn}\left(\mathrm{Me}_{2} \mathrm{EBC}\right)^{4+}$ (initial concentration: $2 \mathrm{mM}$ ) in the presence of xanthene in simple acetone/water (ratio $4: 1$ ) solution at $24^{\circ} \mathrm{C} . \mathrm{k}_{2}=1.75 \times 10^{-3} \mathrm{M}^{-1} \mathrm{~s}^{-1}$. 


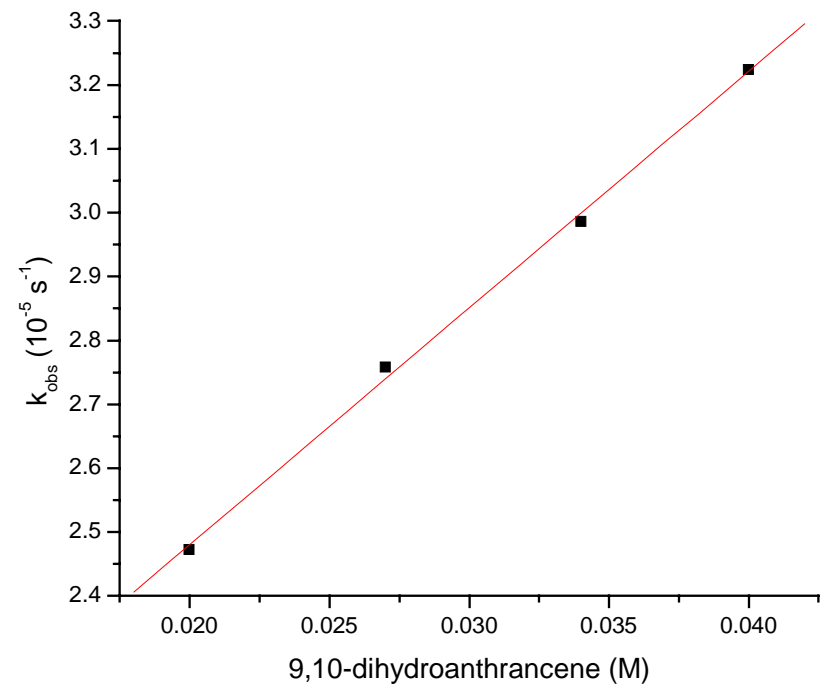

Figure 4S First-order rate constants for the reduction of $\mathrm{Mn}\left(\mathrm{Me}_{2} \mathrm{EBC}\right)^{4+}$ (initial concentration: $2 \mathrm{mM}$ ) in the presence of 9,10-dihydroanthracene in simple acetone/water (ratio $4: 1$ ) solution at $24^{\circ} \mathrm{C} . \mathrm{k}_{2}=3.71 \times 10^{-4} \mathrm{M}^{-1} \mathrm{~s}^{-1}$. 


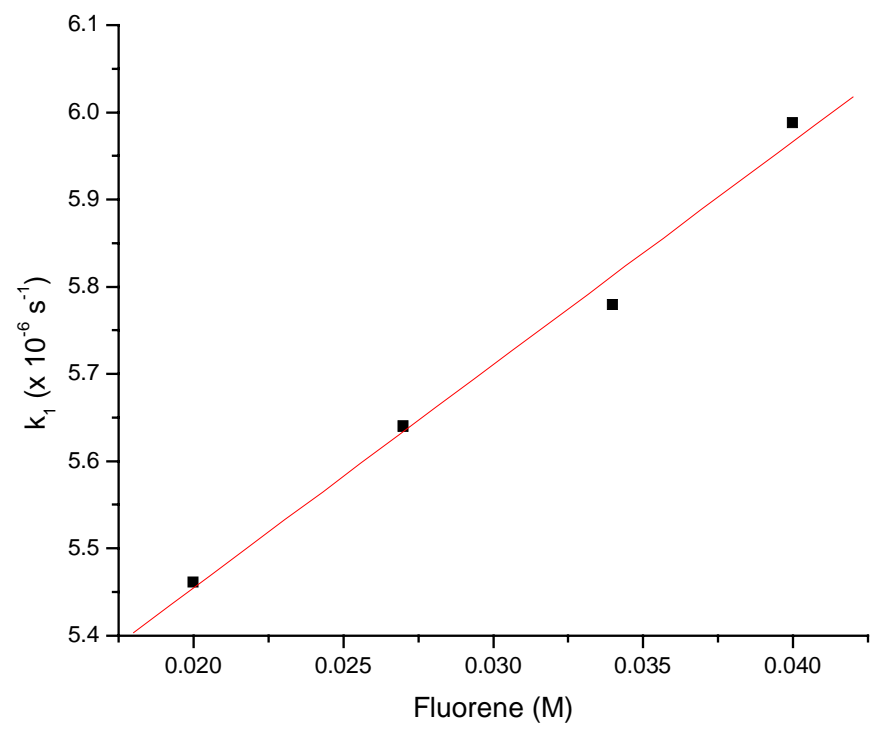

Figure 5S First-order rate constants for the reduction of $\mathrm{Mn}\left(\mathrm{Me}_{2} \mathrm{EBC}\right)^{4+}$ (initial concentration: $2 \mathrm{mM}$ ) in the presence of fluorene in simple acetone/water (ratio $4: 1$ ) solution at $24^{\circ} \mathrm{C} . \mathrm{k}_{2}=2.56 \times 10^{-5} \mathrm{M}^{-1} \mathrm{~s}^{-1}$. 


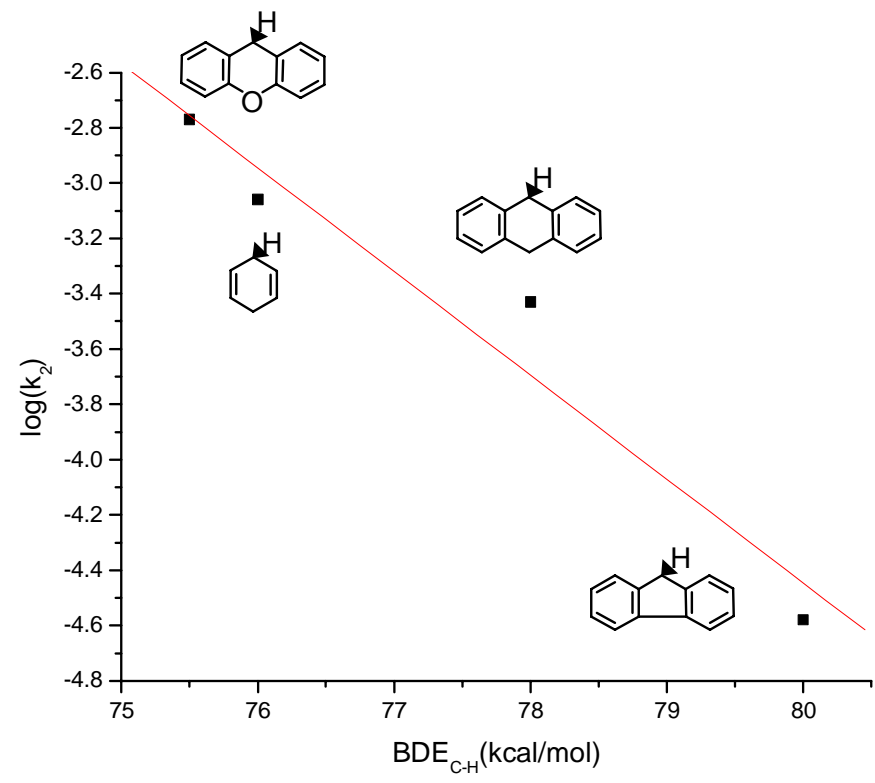

Figure 6S. Plot of the log of the $\mathrm{k}_{2 \text { corr }}$ for hydrogen abstraction vs the BDE of C-H bond. Data obtained in simple acetone/water (ratio $4: 1$ ) solution at $24^{\circ} \mathrm{C}$ 


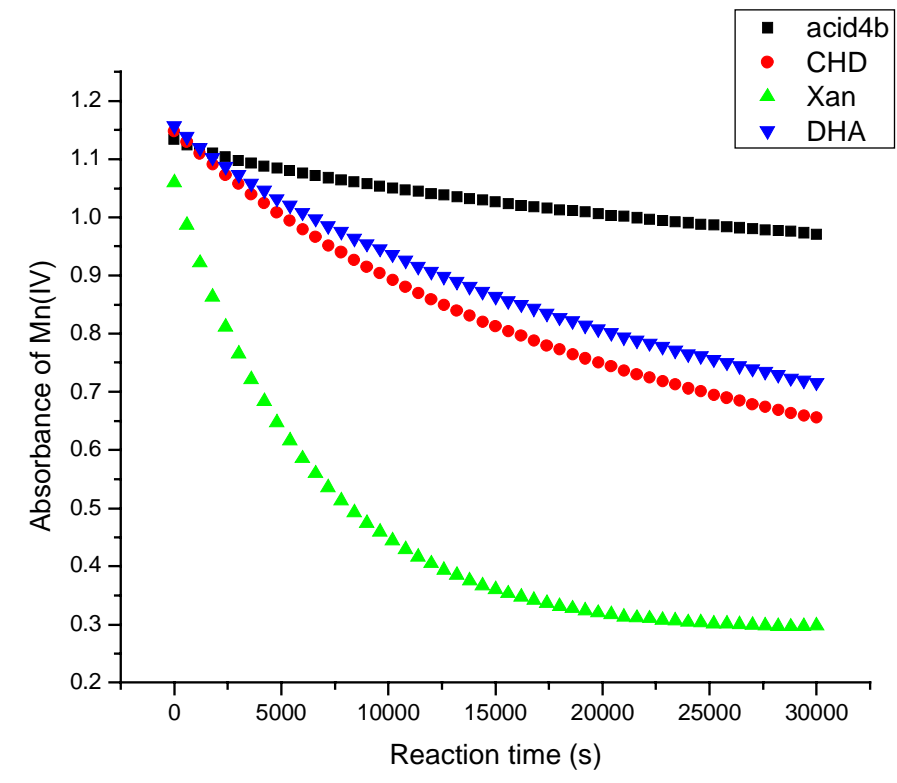

Figure 7S Kinetic process for hydrogen abstraction from different substrates with manganese(IV) complex in acetone/water (ratio $4: 1$ ) with initial $\mathrm{pH}$ of 4.0 at $24^{\circ} \mathrm{C}$. The black line is for a control experiment without substrate. The other lines are the modified plots after corrections based on the black line. CHD: 1,4-cyclohexadiene, Xan: xanthene, DHA: 9,10-dihydroanthracene. 


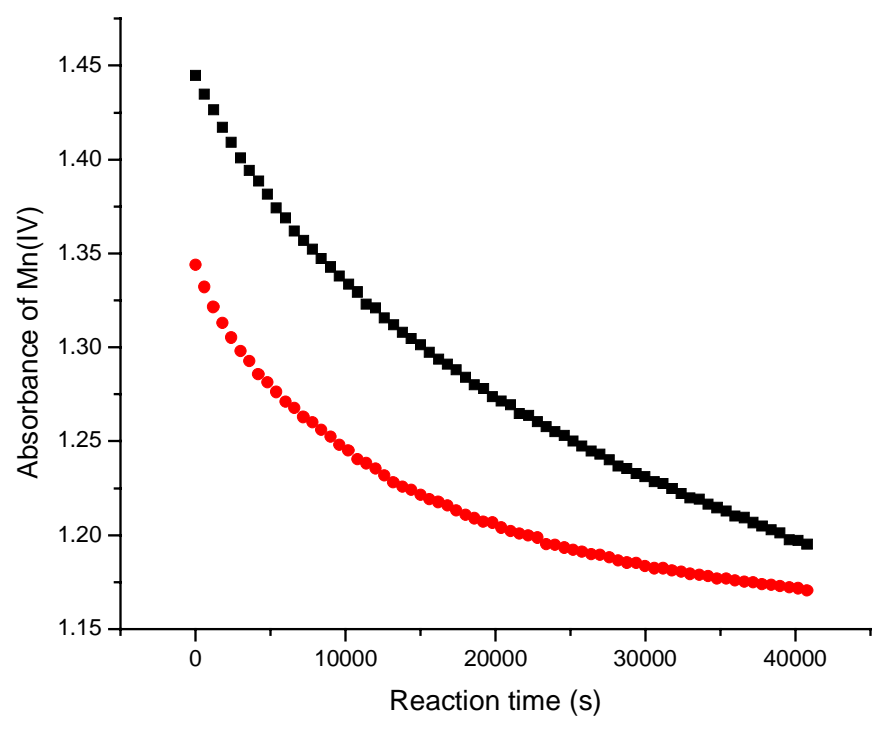

Figure 8S Kinetic process for hydrogen abstraction from fluorene with manganese(IV) complex in acetone/water (ratio $4: 1)$ with initial $\mathrm{pH} 4.0$ at $24^{\circ} \mathrm{C}$. Black line is for a control experiment without added fluorene. $\mathrm{k}_{1}=(2.86 \pm 0.06) \times 10^{-5} \mathrm{~s}^{-}$ 


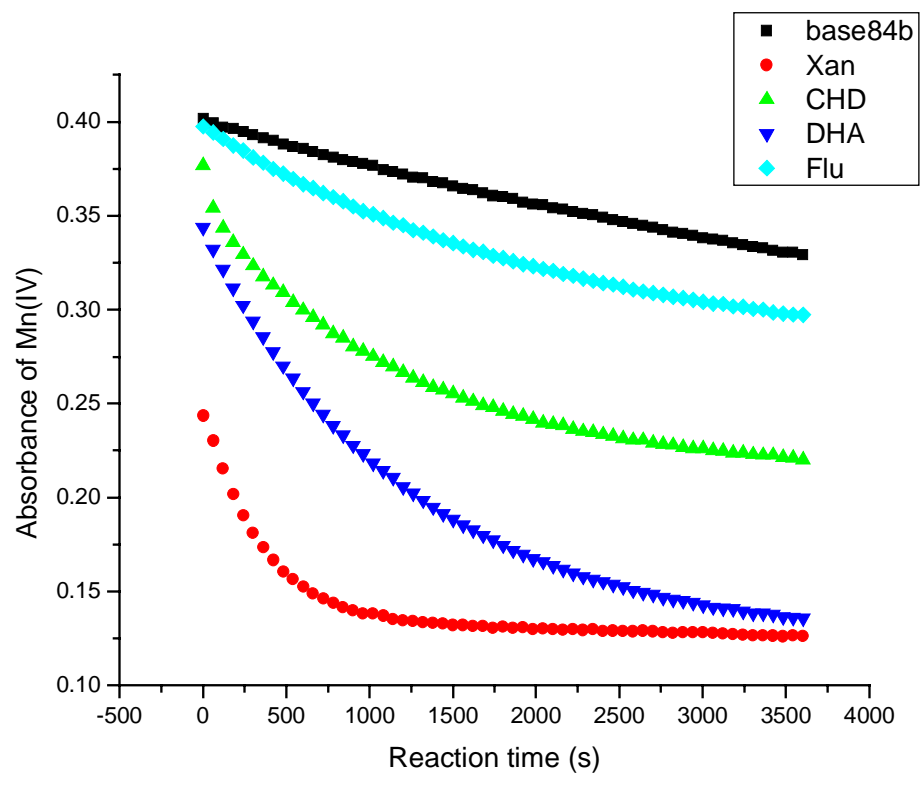

Figure 9S Kinetic process for hydrogen abstraction from different substrates with manganese(IV) complex in acetone/water (ratio $4: 1$ ) with initial $\mathrm{pH}$ of 8.4 at $24^{\circ} \mathrm{C}$. The black line is for a control experiment without substrate. CHD: 1,4-cyclohexadiene, Xan: xanthene, DHA: 9,10-dihydroanthracene, Flu: fluorine. 